\title{
A FIFTY-YEAR CHALLENGE IN MANAGING DRUG ADDICTION IN MALAYSIA
}

\author{
Rusdi AR', Noor Zurani MHR', Muhammad MAZ', Mohamad HH' \\ 'Department of Psychological Medicine, Faculty of Medicine, University of Malaya, 50603 Kuala Lumpur, Malaysia \\ 2 Department of Primary Care Medicine, Faculty of Medicine, University of Malaya, 50603 Kuala Lumpur, Malaysia
}

\section{Introduction}

The history of substance abuse in Malaysia can be divided into pre- and post-independent era. In preindependence, the main drug of abuse was opium which was initially consumed by immigrants from China who were introduced by the British colonialist to work in Malaya. The post-independence era began in the 1960s when young adults were influenced by the "Hippy" subculture. At this time, consumption patterns changed where more Malays were involved in drug abuse compared to other ethnic groups $(I, 2)$.

By the early 1980s, the prevalence of drug addiction increased and this increasing trend made the Malaysian government consider heroin addiction as a national threat. The national anti-drug task force was formed to control trafficking and to rehabilitate addicts who were involved in heroin addiction (3). Legislation was introduced where mandatory death sentence was implemented for those who smuggled more than 15 grams of heroin. Drug addicts found to be positive for heroin were forced to undergo compulsory rehabilitation for two years (4). Nationwide, up to 28 government drug rehabilitation centres were established, and at any particular period, each centre accommodated up to 500 inmates. Approximately RM50 million a year was spent to run these centres (5). The centres were initially managed on a total abstinence philosophy; however this approach produced poor results. The latest survey showed that $85 \%$ of drug addicts relapsed after completing their rehabilitation at these centres $(4,6)$. In view of the poor results, substitute treatment with methadone was introduced recently to these centres (7).

One of the visions of the Malaysian government was to create a drug addiction free nation by the year 2015 . However, the increasing number of drug addicts has caused a surge in demand for rehabilitation centres, resulting in the inability of these centres to cope. For example, the number of drug addicts increased by I\% from year 2001 to 2002 , but the number of drug addicts detected in year 2003 was 36,996, a $16 \%$ jump from the previous year $(31,893)$. Furthermore, the National Drug Agency reported that $45 \%$ of the cases were repeat addicts. As for distribution of new cases, by ethnic group the Malays constituted $71 \%$, Chinese $10.6 \%$ and Indian $8.2 \%$. The majority $(70 \%)$ were in the socially and economically most productive age group (20-39 years) and almost $98 \%$ of the addicts who occupied these rehabilitation centres were male. Currently, the number of drug users in the country is estimated to be 250,000 but the number is predicted to reach half a million by year $2015(3,8-10)$. The resulting economic, human resource and social loss is not quantifiable as the vacuum left by these people in various employment sectors are currently being filled by migrant workers. Thus, it is evident that the increasing trend in drug addiction poses a threat to the future of the nation $(1,6,9)$.

\section{Challenges to Treating Drug Addiction in Malaysia}

Substance abuse is one of the leading and most complicated health and social problems faced by our country. Unfortunately, after three decades of managing these problems, outcomes are unpromising and poor. This could be due to several reasons. Firstly, treatment policy has been confined to a single treatment modality, which is the regimental rehabilitation programme. Secondly, the medical therapeutic approach has been totally ignored by this policy, despite strong evidence that addiction to drugs is a medical condition. It was only recently that the medical profession was called to review the treatment policy and provide input in the management of addiction in Malaysia. Thirdly, it is the

\footnotetext{
Correspondence:

Rusdi AR

Department of Psychological Medicine

Faculty of Medicine

University of Malaya

50603 Kuala Lumpur, Malaysia
} 
stigma of the illness and rehabilitation treatment itself, which has resulted in patients being hesitant of seeking early treatment. It was reported that there is the fear of rejection by the community and losing their freedom once they enter a rehabilitation programme in Serenti Centres $(6,7,9)$.

As everyone who enters the Serenti Centre is required to undergo rehabilitation and be detained for two years, this causes the inmates to be deprived of work. Most of them have to give up their occupation during detention and by the time they leave the centre, they lose their opportunity to work. This could be one explanation why many of them resort to crime once they are discharged from the Serenti Centre. Some addicts reported that they perpetrated crime in order to support themselves and their families. However, this reason is only part truth as it was found that many did it to support their addictive habit. This is because they abstained from taking drugs while in the Serenti Centre, but the rehabilitation centres do not cure them of the illness. Therefore, once discharged from the centre, they relapse $(6,7,9)$.

The types of crimes reportedly done by drug addicts are snatch theft, selling drugs, fraud, house breaking, homicide and suicide. The involvement of drug addicts in crime could lead them to be imprisoned. Imprisonment adds another problem as it further stigmatises the drug addict since the community take this as confirmation that drug addicts are hard-core criminals. This leads to a total rejection from their families and the community. The drug addict thus loses hope and eventually becomes depressed. As a result of family rejections the only person they can confide in is other drug addict peers. This is also the time when addicts share needles, thus worsening the addiction problem. This process may explain the whole cycle of addictive behaviour and how it is associated with HIV and AIDS $(I, 6)$. It is very unfortunate that in the past, the medical community dealt with these addicts when they have already contracted these horrendous complications. The consequence of past inappropriate policies is a continually increasing number of infectious diseases among people who use drugs and an escalating incidence of HIV or AIDS in Malaysia. It has been reported that the cumulative number of HIV infections reported to the Ministry of Health Malaysia up to December 2005 was 70,559 cases with 8, 179 positive for AIDS. Most (8I.5\%) of the HIV infected persons were young males (age 20-40 years) $(1,6,7,9)$.

The effect of failed treatment in Serenti centres affects the addicts and cause misery to their family members as $50 \%$ of drug addicts undergoing rehabilitation programmes are sole breadwinners. The impact of losing their sole breadwinner for two years caused extreme financial and emotional hardship, and stress in the family system leading to family disruption. This could be one explanation why children of drug addicts are at more risk of becoming drug addicts $(6,7,9)$.

Due to needle sharing, families of addicts are also at risk from HIV and AIDS. There are reports where drug addict husbands, infected with AIDS, transmit the disease to their spouses and children. This is another disaster, which could have been prevented from the beginning if the addiction cycle that was worsen by the Serenti form of rehabilitation was stopped and replaced $(6,7,9)$. Therefore, is it past time that the Serenti rehabilitation programme be reviewed?

There has been much concern expressed by the public as well as by professionals about the failure of the Serenti treatment programme in tackling heroin addiction in Malaysia. It is, therefore, timely for the government to evaluate the cost-benefit of the Serenti rehabilitation programme. Among the first consideration should be the duration and the type of drug addict who needs the treatment. It is suggested that the duration of stay in Serenti should be shortened from 2 years to about 3 to 6 months. There are many advantages of shortening the rehabilitation period $(6,7,9)$. Firstly, this ensures that addicts will be able to go back into the community without depriving them of their potential either as workers or breadwinners of the family. Secondly, this is cost-saving for the government. It was reported that the government paid RM3000 to maintain one addict in a Serenti Centre for a month. Reducing the stay to six months will incur only a quarter of the cost incurred currently. Nevertheless, the most expensive cost is still borne by the drug addicts' familieswho suffer financial and emotional loss at being left without anyone to look after needs. This loss is of course unquantifiable in ringgit and cents $(6,7,9)$.

\section{The Present}

Realising that the occurrence of HIVIAIDS among addicts were out of control, the national drug substitution task force was set up to control the problem. Although the suggestion was introduced in 2000 , it was only fully implemented in 2005. The objective of this task force was to review the role of drug substitution treatment in order to prevent the spread of HIV, especially among heroin addicts. The success of its implementation was mainly due to concerted efforts made by the Ministry of Health, Malaysia, the Universities and nongovernmental organisations (NGOs) who lobbied for it to be implemented quickly $(6,7,9)$. The matter was urgently lobbied to ensure minimal bureaucracy or red tape. One of the procedures was a national study on methadone maintenance treatment. The study involved I 200 hard core drug addicts who were given free 
methadone treatment from selected government and private clinics. While on methadone, the patients were also requested to attend regular counselling session by the national anti-drug task force (AADK). This was the first arrangement at the national level where doctors, NGOs and AADK officers met and delivered a very comprehensive treatment programme for addicts $(1,6,7)$.

The result of the study showed that methadone maintenance therapy improved compliance to treatment programmes. In many centres, the level of compliance reached $80 \%$. The advantage of this study was not only confined to improved retention rate but it also offered patients normal functionality and a good quality of life. For example, a case of Mr ZM, a 40-year-old single man who had been involved in drug addiction for 20 years and had undergone many rehabilitation programmes, but still failed to stop taking drugs; he had been through the rehabilitation programme in Pengasih, which claimed to cure many addicts. He visited the centre more than twice to get treatment but was unsuccessful. He only managed to stop taking heroin after he joined the methadone maintenance programme at the University of Malaya Medical Centre (UMMC) Addiction Clinic. A few months after the programme, he managed to get a job as a clerk and was no longer supporting himself through illegal activities. He also managed to go back to his family and even to contribute his income to their financial needs; though unfortunately by this time he was tested positive for HIV and hepatitis C. This is not the only story where patients like Mr ZM had to go through ineffective programmes before they came into our centre to get treatment. It is also very unfortunate that many of these patients were already HIV and hepatitis $C$ positive by the time they sought treatment at the Addiction Clinic. The worst horror was when Mr ZM informed the team how he had been sharing needles, which were probably contaminated with this virus, with more than 20 addicts. Imagine how many among them are now potential virus carriers, and how many of them have transmitted the disease to others! If this pattern of transmission continues, there will be a time when Malaysia will share a similar fate with some Western African countries where HIV has almost eradicated their young productive population $(6,7,9)$.

The experience at the UMMC Addiction Clinic also shows that many of the drug addicts managed to resume their social and family responsibilities. The team highlights another case of Mr R, a 40-year-old man who after chronic involvement with drugs became a burden to his family. He was never employed and his family always sent him to rehabilitation centres each time he went back on drugs. Fortunately one of his family members knew about the methadone maintenance programme, and he was referred for treatment. It only took him six months before he managed to overcome his craving and "cured" himself finally of drugs. Although he is still on treatment, he is now able to manage his family business and no longer steals his parent's money.

The cost of treating heroin addicts using a medical-based approach is also cheaper. For example, patients only need about RM 400 per month if they are undergoing drug substitution therapy. This is in contrast to longterm rehabilitation, which costs about RM3000 per month. If we include the quality of life and other indirect costs like the family burden, the cost of managing drug addicts in rehabilitation will definitely be much more than the direct costs $(6,7,9)$.

A major cost will be incurred if they have already contracted hepatitis or AIDS. For example, the cost of treating drug addicts who have hepatitis $C$ is about RM 15,000 per month. Imagine the burden of cost to the addicts if they had contracted the virus. Since most of them will not be able to afford to pay, there is a possibility that the cost will be financed by the government and this may place a financial burden to the nation.

The other advantage of allowing drug addicts to be treated under a drug substitution programme is the opportunity for training (e.g., job-placement training) and counselling (psychological counselling or spiritualbased counselling). During drug substitution treatment, the drug addicts are free from withdrawal or intoxicating effects due to heroin. This is advantageous as it puts them in a better position to participate and concentrate on rehabilitation and training $(6,7,9)$.

\section{The Future}

There have been many claims made about the ability to cure addiction, but in reality evidence show even the most elaborate forms of treatment produce minimal success (less than 10\% effectiveness). This is because addiction is a chronic relapsing disorder and requires multiple treatment programmes and longterm treatment modalities. Most often, treatment approach require psychological and social intervention with additional pharmacological treatment. It has been reported that treatment programmes which confine only to rehabilitation programmes like those in Serenti centres, produce poor results and inefficient use of public funding $(6,7,9)$. As mentioned above, in Malaysia, after many years of experimenting with social treatment and ignoring medical input, the drug addiction problem has not only escalated but has exposed our society to the danger of the HIV and AIDS epidemic. 
Thus, the 50th year of our Independence is, therefore, timely for us to rethink of a new approaches forward by combining the medical and psychosocial approach in managing the addiction problem in Malaysia. It is the hope for present and future generations to continue enjoying an independent Malaysia without succumbing to drug addiction. Otherwise, a situation may arise in which the next generation will die prematurely or lose their potential to maintain what we currently enjoy. This is because addiction to drugs is like a silent virus that, once established, can make our whole generation be enslaved by their addicted brain.

\section{Conclusion}

The way we handle addiction problems in Malaysia has gone through various processes. Rehabilitation programmes involving detention centres were first introduced, and it was only towards the late 1990s when it was realised that the success rate was almost negligible and analysis showed that monotherapy like rehabilitation produced poor success rate. The Malaysian government has now opened up policies involving new ideas in dealing with drug addiction. Drug substitution therapy, a new approach to dealing with drug addicts is the future of managing drug addiction in Malaysia.

\section{References}

I. Chawarski, MCM, Schottenfeld, RSM. Heroin dependence and HIV infection in Malaysia. Drug Alcohol Depend 2006; 82:39-42.
2. Navaratnam, VF. Natural history of heroin addiction and adjunctive use, in Research Report Series. 1988; 16, National Drug Research Centre, University Science Malaysia: Penang, Malaysia.

3. National Narcotics Report. Ministry of Health, Malaysia. National Narcotic Agency: Kuala Lumpur; 1998.

4. Navaratnam, VF, Kulalmoli, SK. An evaluative study of the drug treatment and rehabilitation programme at drug treatment centre in Centre for Drug Research UN/WHO/IFNG Research and Training Centre, University Science Malaysia: Penang; 1992.

5. National Anti-Drug Agency. Ministry of Home Affairs, Malaysia. Available from: www.adk.gov.my. I 3 January 2008.

6. Chawarski, MCM, Schottenfeld, RSM. Behavioural drug and HIV risk reduction counselling (BDRC) with abstinent-contigent take-home buprenorphine: A pilot randomised clinical trial. Drug Alcohol Depend 2007.vol: pp?

7. Mazlan, MS., RS. Chawarski, MC, New challenges and opportunities in managing substance abuse in Malaysia. Drug Alcohol Depend 2006; 25(473-78).

8. Prison Statistics Report. Prison Department of Malaysia; 1996.

9. Habil, H. Managing heroin addicts through medical therapy. Kuala Lumpur: University Malaya Press, $200 \mathrm{I}$.

10. Karofi, UA Drug abuse and criminal behaviour in Penang, Malaysia: A multivariate analysis. Bangladesh e-journal of Sociol 2005; 2(2): I-26. 